\title{
A word-superiority effect with print and braille characters
}

\author{
LESTER E. KRUEGER \\ Ohio State University, Columbus, Ohio
}

\begin{abstract}
Braille (tactual) text is read only about one-third as rapidly as print (visual) text, but the same basic cognitive processes may be involved in both cases, because familiarity aids letter search in a similar fashion for the two modalities. Experiment 1 found that with grade 1 braille, as with print, letter search is about $10 \%$ faster through common words than through nonwords. Thus, braille, like print, is processed in neither an entirely holistic manner, with the word gestalt concealing its letter components, nor in an entirely analytical manner, with each letter dealt with separately and independently. Experiment 2 (print displays) and Experiment 3 (braille displays) both found a word advantage in letter search through words and nonwords containing no spelling patterns that form contractions in grade 2 braille. Experiment 2 also confirmed previous work showing that the time savings for words does not vary when the memory set size (number of predesignated target letters) is varied. This indicates that the word advantage is at encoding rather than comparison.
\end{abstract}

The present study tested whether letter search would be faster through words than through nonwords with braille (tactual) presentation, as has been found with print (visual) presentation (Krueger, 1975). Finding a similar word advantage for braille and print not only would shed light on the braille reading process, but also would open the way to apply other tasks developed with print materials to the study of the braille reading process. Experiments 1 and 3 used braille characters; Experiment 2 used print characters to obtain norms for Experiment 3 and, in addition, investigated the locus of the word advantage in letter search.

It was not all clear when this study was begun whether a word advantage would, indeed, be found with braille characters. Braille is much more difficult to read than print. Experienced sighted readers typically read 250 to 300 words/min, but experienced braille readers read only 80 to 100 words/min (Foulke, 1982; Nolan \& Kederis, Note 1), or about one-third as fast. One reason for the slower braille reading is that hand movements are involved. Another is that tactual acuity is much poorer than vi-

This study was supported by National Institute of Mental Health Grant MH32295. The author is grateful to Marjorie Ward for making available a Perkins Brailler and for assistance in devising grade 2 braille materials, to Bryan Connell, Ernest W. Hallford, and Stanley H. Radzio for assistance in preparing the stimuli, to Bryan Connell, Robert Hilkert, and Sehchang $\mathrm{Hah}$ for assistance in collecting the data, to Fred and Betty Gissoni of the Center for Independent Living, Louisville, Kentucky, for assistance in enlisting and testing braille readers, and to Emerson Foulke, Neal F. Johnson, James C. Johnston, Ronald G. Shapiro, and Marjorie Ward for helpful comments and suggestions. Requests for reprints should be sent to Lester E. Krueger, Human Performance Center, Ohio State University, 404-B West 17 th Avenue, Columbus, Ohio 43210. sual acuity, and the tactual field of view is much smaller than the visual field of view (Foulke, 1982; Loomis, 1981). In vision, letters are encoded by parallel, independent processing channels (Krueger \& Shapiro, 1980a; Shiffrin \& Gardner, 1972). In touch, by contrast, letter and pattern detection actually declines if the index finger is accompanied by the adjacent middle finger, which is stimulated simultaneously by a different pattern (Hill, 1974; Lappin \& Foulke, 1973). Spatial properties, such as extent, location, and orientation, are detected less readily with touch than with vision (Millar, 1978; Révész, 1950).

The poorer tactual acuity might force braille readers to deal with the overall outline of the word, since the details of the component letters would be less available. Touch is dependent on movement, and this, too, may make it better suited to picking up global properties, such as texture, than local properties, such as shape or contour (Katz, 1925; Krueger, 1970a, 1982). The whole word thus might be more perceptible than its letters, and it might thereby overshadow and conceal rather than reveal the letters. When a braille word is scanned by the fingertips, "the skin is thereby presented with a detectable higher order invariance or spatiotemporal structure, although ... the structure is not optimally designed or utilized in the braille code' (Kirman, 1973, p. 67).

In print, the whole-word theory has had many adherents (e.g., Johnson, 1975; Theios \& Muise, 1977), beginning with Cattell (1886), who found that no more time was needed for the identification of a whole word than for that of a single letter. Pillsbury (1897) said that in a brief presentation of a word, "the rush of recognition may be so violent that the letters themselves are entirely neglected-forgotten, 
or not seen at all" (p. 378). According to Nolan and Kederis (Note 1), braille teaching practices have shifted in accord with changes in print teaching practices, and "it appears that most teachers of braille consider the whole word as the unit of recognition, and that the word is perceived on the basis of its overall shape or form"' (p. 18).

However, practically all research on braille has "emphasized the effects of certain characteristics of the individual characters and even the dots on ordinary reading and the recognition of words and characters" (p. 20). Nolan and Kederis therefore proposed that braille words are read on a character-bycharacter basis, and that "the perceptual unit in braille reading is the individual braille character" (p. 152). They found that training in character recognition improved braille reading, whereas training in whole-word recognition did not. They also found that the time needed to identify a braille word depended on its length, both for familiar words and unfamiliar words, and that the time spent identifying a word exceeded (by 16\% to 196\%) the sum of the identification times for its constituent characters.

Foulke (1982) concluded from these results that the typical braille reader can acquire information on only one character at a time; occasionally, a word may be identified without identifying all of its characters, but generally "the braille reader must have to identify and remember all the letters in a word, and then integrate them in order to identify that word" (p. 194). Only a few, exceptionally fast braille readers can identify braille patterns with enough temporal extension to encompass entire words, according to Foulke. Kirman (1973), similarly, said that "the difficulty with braille ... is that the successive stimuli are not related to one another in any coherent manner and no extended spatiotemporal pattern can emerge from their sequential presentation" (p. 70).

A third possibility is that braille reading is neither entirely holistic nor entirely analytical and that the same basic processes that occur in reading print occur in reading braille. Nolan and Kederis (Note 1) found that their subjects typically recognized $10 \%$ to $20 \%$ of the words before all the component letters were felt. Pick, Thomas, and Pick (1966) found that pronounceable braille pseudowords were spelled aloud faster and more accurately than unpronounceable ones. The latter effect may have been at the response (spelling aloud) stage, rather than at a perceptual stage, however.

\section{EXPERIMENT 1}

In Experiment 1, braille readers searched for a single letter through a list of words or nonwords. If braille reading is so analytical that only one letter can be attended to at a time, then letter search ought to be equally fast through words and nonwords. Nolan and Kederis (Note 1) reported that the "recognition of braille words is [a] far slower process than recognition of individual braille characters which is exactly opposite to the behavior of sighted readers" (p. 84). They conceded, though, that "some of [the] integration [process involved in word recognition] very probably occurs during the movement from character to character within a word" (p. 84), especially for familiar words, because less additional time was needed for word recognition when word length increased. "For longer words, the accumulation and integration of information as the characters are covered allows for recognition before, at the time of, or soon after encounter with the last character" (p. 85). However, even for familiar seven-letter words in their Study II, the word recognition time exceeded the sum of letter recognition times by about $20 \%$, for both fast and slow readers. Given these results, letter search might be much faster if the subject did not try to deal with the words as words, but treated both words and nonwords as collections of unrelated letters. Conversely, if the overall gestalt or word pattern dominates, letter search ought to be even slower through words than through nonwords.

Only if neither analysis nor fusion dominates will a target braille letter be perceived more readily in words than in nonwords, as occurs with print characters (Krueger, 1970c, 1975). The letter search task provides a sensitive measure of the ability of braille readers to use familiar context to speed letter identification. To benefit from the familiar context, the subject in the present task need not infer an entire word, but may merely attend to local spelling patterns, such as bigrams and trigrams (Krueger, 1970c), and he or she does not have to report all of the letters perceived.

\footnotetext{
Method

Stimulus materials. Braille characters, or cells, each a matrix of three rows and two columns of possible raised dots, were embossed on sheets of paper by a computer-driven printer. A separate set of sheets was prepared for each subject. The height and spacing of the braille characters somewhat exceeded that of standard braille characters (see Experiment 3 ). Each character, or cell, was $.4 \mathrm{~cm}$ wide and $.75 \mathrm{~cm}$ high; the horizontal separation between adjacent cells was $.4 \mathrm{~cm}$, and the vertical separation between adjacent (double-spaced) rows was $1.75 \mathrm{~cm}$.

Each display contained five rows of five six-letter items each, or 25 words or nonwords in all. A period and blank space preceded each row as a reference point. Krueger's (1970c) sets of $140 \mathrm{com}$ mon six-letter words and 140 corresponding nonwords were randomly sampled to devise the displays. A target letter, preceded by the word "target," was located above the first row of each display. The target letter appeared 0 or 1 time in the display itself. Eighteen displays of words were devised by placing the target letter once each in every even-numbered display position, that is, 2 to 24 , which required 12 displays, and excluding it in six (("catch") displays. Each of the 18 displays of nonwords was devised so as to match a given word display; it contained the same target letter in the same serial position within the same display position. The order of presentation of the 36 displays was randomized, and an additional 4 displays were presented first as practice.
} 
Procedure. The subjects first inspected the target letter, and then began scanning when told to "go"' by the experimenter, who timed the search with a stopwatch calibrated to $.1 \mathrm{sec}$. The subjects were asked to search as rapidly as possible, but not at the expense of accuracy, saying "hit" as soon as they felt the target letter or "not there" after the last row. They were told whether they had failed to detect a target that was there or had reported a target on an incorrect row. Search time was based on correct trials.

Subjects. Seven blind adults, who were familiar with braille and ranged in age from 19 to 30 years, served as volunteer subjects. Data from two additional subjects were excluded because their errors exceeded $10 \%$. A sign test found no significant difference between corresponding word and nonword displays for either of these two subjects.

\section{Results}

The subjects searched faster through word than through nonword displays $[\mathrm{F}(1,6)=23.33, \mathrm{p}<.01]$. Furthermore, most subjects, not just the exceptional braille readers (cf. Foulke, 1982), showed the effect. Two-tailed sign tests of the search time difference between the 18 corresponding word and nonword displays (excluding any pair containing an error) indicated that the speed advantage for words was very significant for two subjects $(\mathrm{p}<.001)$, highly significant for two $(p=.007)$, quite significant for one $(p=.021)$, and not significant at all for two $(p>.20)$.

As Figure 1 shows, the word advantage steadily increased as the target letter was placed further into the list. Target position (early, late, not present) interacted significantly with the word-vs.-nonword factor $[F(2,12)=4.61, p<.05]$, confirming the progressive increase in the word advantage. Time savings for word displays averaged $11.27 \%$ overall and remained at about this level for most target positions, as Figure 1 shows.

Mean errors did not differ significantly between words $(4.76 \%)$ and nonwords $(6.35 \%)$. Three subjects made more errors on nonword displays, two made more errors on word displays, and two made an equal number on both types of display.

\section{Discussion}

The present findings give no indication that braille words conceal their component letters, as the wholeword model would predict. On the contrary, the findings indicate that experienced braille readers can utilize the familiar context of words to speed their search for braille letters. Whatever sensory or perceptual factors make braille reading so slow, they do not eliminate this ability. Thus, braille, like print, is processed in neither an overly holistic fashion nor an overly analytical fashion. An even closer similarity between braille and print may be noted in that the percentage of time savings for common words (about $10 \%$ ) found previously for print (Krueger, 1979; Krueger, Keen, \& Rublevich, 1974) was the same as that found here for braille.

The present subjects searched about three times as slowly as sighted adults who were presented with a

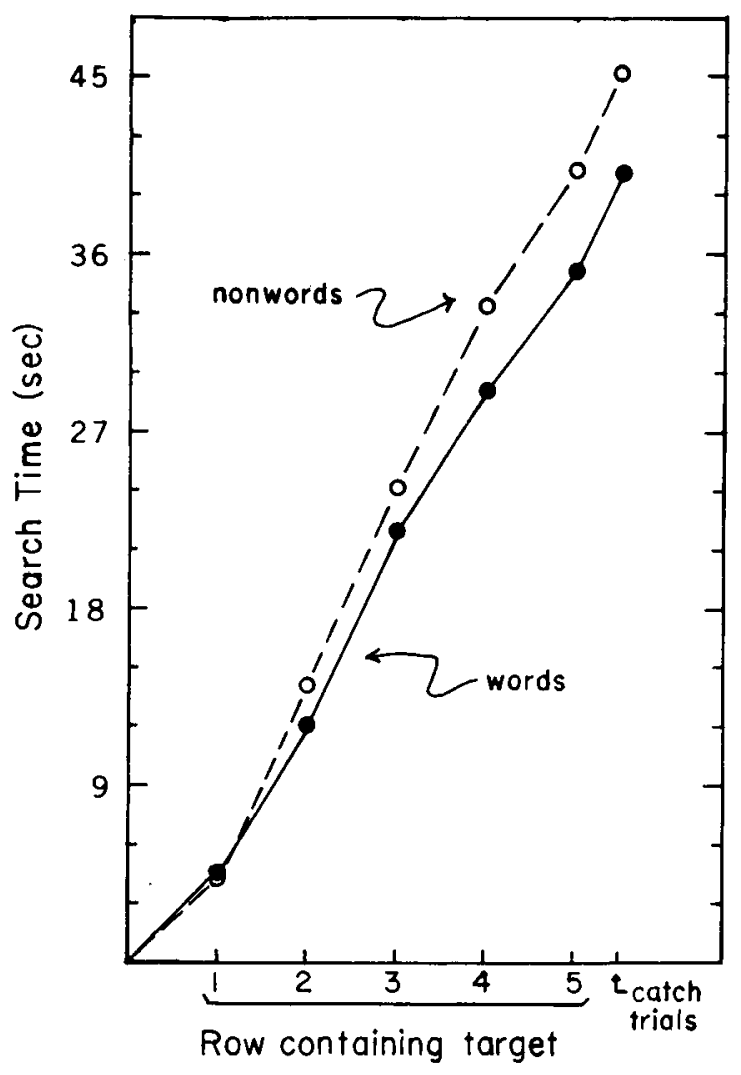

Figure 1. Experiment 1: Mean search time (seconds) by row position of target letter.

similar, 25-item display (Krueger, 1970c). This is about what would be expected, given that braille text is normally read only about one-third as fast as print text (Foulke, 1982; Nolan \& Kederis, Note 1).

The characters presented in Experiment 1 were somewhat larger than standard braille characters, and somewhat fainter as well, since they were embossed on ordinary paper. In addition, grade 1 braille was used, which meant that letter sequences which form single-cell contractions in grade 2 braille were fully spelled. Practically all schools use grade 2 braille from the beginning (Nolan \& Kederis, Note 1), so the attention of the subjects in Experiment 1 may have been disrupted when they encountered familiar letter sequences presented in atypical (fully spelled) fashion. This may have prevented them from perceiving the words in normal fashion, which might have been as wholes. To test for the word advantage under more normal conditions, the following tests excluded letter sequences which form contractions in grade 2 braille. In order to keep words and nonwords at the same, fixed length (six characters each), only the 26 characters representing individual letters, and no characters representing contractions, were presented. Experiment 2 tested the new words and nonwords in a print task. Experiment 3 used the new materials in a braille 
task in which normal-size characters were embossed on heavyweight manila paper or plastic sheets (Thermoform copies).

\section{EXPERIMENT 2}

Experiment 2 served two purposes. First, it determined whether a word advantage with print characters would still be found with the new set of words and nonwords. The new items contained no contractions in grade 2 braille, and eliminating the familiar letter sequences that form such contractions might make the words no easier to deal with than the nonwords, in which case there would be little point in running Experiment 3 to test for a word advantage with braille characters.

Second, Experiment 2 provided an important further test of whether the word advantage was at the encoding, rather than the comparison, stage. With practiced subjects, Krueger (1970c) found that the time savings per word remained the same regardless of whether the subject searched for 1,2 , or 3 target letters. These results favored an encoding locus of the word-superiority effect, since a comparison locus would have predicted a progressive increase in time savings as the number of target letters increased. With unpracticed subjects, however, Krueger (1969) and Greenberg and Krueger (Note 2) found that the word advantage did not remain constant, but decreased, as the memory set size increased. However, in all tests run thus far, the subject either had to respond to each word or nonword (Greenberg \& Krueger, Note 2) or was shown only two words or nonwords at a time (Krueger, 1969, 1970c), and with so little encoding involved per response, any word advantage present at encoding might well be obscured by variability at other stages.

The present search task provided a more sensitive test, as well as a greater incentive for subjects to utilize the familiarity inherent in words, by having the search involve not 1 or 2 words, but 25 , so even a slight time savings per word would be compounded into a sizable and important overall savings. Furthermore, the larger display would provide a potentially valuable preview (Greenberg \& Krueger, Note 2; cf. also the eye-voice span in reading, Levin \& Kaplan, 1970 ), allowing the subject to work ahead on encoding, while the comparison operation dealt with several preceding words or nonwords (cf. Fischler, 1975; Sternberg \& Scarborough, Note 3), and this, too, would favor faster encoding of words. Search for more than one target letter makes the task quite difficult, but given the incentives provided, subjects may very well make the extra effort required to encode the words as words.

\section{Method}

Apparatus. Letters were presented, at a $60-\mathrm{Hz}$ refresh rate and at $32 \mathrm{~cd} / \mathrm{m}^{2}$ intensity on a greenish-tint, fast-decay $P 31$ phosphor (decay to $1 \%$ intensity at $.25 \mathrm{msec}$ after display offset), by an Imlac PDS-4 graphics computer, which measured RT to an accuracy of $1 \mathrm{msec}$. The letters, presented as thin, illuminated lines on a dark screen, were software generated, using short line vectors, so as to resemble normal English uppercase letters. Each subject sat alone in a dark room, with his or her head held fast in a chinrest located $70 \mathrm{~cm}$ from the display screen.

Stimulus materials. Each display contained five rows of five six-letter words or nonwords. Each uppercase letter was $.29 \mathrm{~cm}$ wide and $.43 \mathrm{~cm}$ high; $.19 \mathrm{~cm}$ separated adjacent letters, and $1.09 \mathrm{~cm}$ separated adjacent rows. The overall display was $6.53 \mathrm{~cm}$ (5.36 deg) high and $14.48 \mathrm{~cm}$ (11.82 deg) wide.

The word set was devised as follows. The 100 most frequently occurring English words with six different letters and no letter sequences forming grade 2 braille contractions were obtained from the Kucera and Francis (1967) word count. The words thus obtained (see Table 1) all had a frequency of 21 or more per million words. The nonwords (see Table 2) were formed by randomly permuting the 100 letters within each of the six letter positions,

Table 1

Experiments 2 and 3: Common Six-Letter Words Containing No Contractions in Grade 2 Braille

\begin{tabular}{lllll}
\hline SIMPLY & HUNGRY & FAMILY & NATURE & FIGURE \\
PRISON & VOLUME & SOCIAL & BRIDGE & DESIGN \\
SECOND & SURELY & TRAVEL & WISDOM & RESULT \\
DIRECT & NORMAL & FISCAL & FACTOR & PLACES \\
DETAIL & FIELDS & MORGAN & COLUMN & MELODY \\
BUDGET & NOTICE & SAMPLE & SYMBOL & WIDELY \\
PANELS & POCKET & WATSON & MOBILE & MUSCLE \\
HOLMES & IMAGES & SURVEY & DUTIES & PHRASE \\
MOVIES & PURELY & VIRTUE & LADIES & MICKEY \\
ANGELS & GRADES & PLATES & RIFLES & VICTOR \\
SELDOM & EASILY & FIRMLY & FAIRLY & POLICY \\
GUILTY & SIMPLE & PUBLIC & LIQUOR & ORANGE \\
OBJECT & HUDSON & ADVICE & VALUES & POLICE \\
ACTIVE & POETRY & REGION & JUNIOR & CLAIMS \\
IMPACT & SIGNAL & WILSON & PRICES & JOSEPH \\
MANTLE & MODELS & SAFETY & ATOMIC & NATIVE \\
UNLIKE & WRITES & TRIALS & VOICES & BLOCKS \\
SAMUEL & CAMPUS & JACKET & TRAGIC & MATURE \\
FRAMES & PLANES & PATROL & RITUAL & SUBTLE \\
MOTIVE & NOVELS & REFUND & TRUCKS & PLANET \\
\hline
\end{tabular}

Table 2

Experiments 2 and 3: Six-Letter Nonwords (Corresponding to Common Words) Containing No Contractions in Grade 2 Braille

\begin{tabular}{lllll}
\hline MURCNS & PIAMES & AEMICL & CIVUAL & PROGLS \\
PBFAES & OIAUGS & RIEUOY & SOLDAE & TLGMEY \\
SDVIEY & MITPEY & PACNLH & FOLMUN & LRDIMS \\
RLSNID & MILDRE & FAMELS & PAITLR & MTLCES \\
MECIOS & SOBIES & BUMPOS & SODPCE & GUNRLS \\
CURIGM & NIRKMC & BOLTCY & PETLAN & FIREOS \\
PASUVL & DACIEL & VUSIET & TASMEL & HLAIVE \\
PANIET & NOACGE & DETULR & WRACET & FYSEOT \\
IAJKNE & OEAILN & MLTEON & SUANTY & PIMSRE \\
FRLSIE & JOMSLE & WIFVDE & NOLUES & VIAELR \\
PUAIKY & MURPOC & SAUEIL & TUIASN & FOTGCS \\
UAIGET & GIFVEL & RCTLON & RODIKC & SUEIOL \\
FMRTLS & PMRTOS & HORTLY & DAMILS & VONLET \\
WRGAEM & SUNIAE & VOTGCR & CRSDIE & MLVIRE \\
BNTCOE & SAICOY & PABMEL & SACTLN & TRCIVD \\
AILUES & JRSKEL & HOTUAE & MODULY & PHAGUE \\
LNIADY & FIAEKY & NIMEOS & REITLS & JITORS \\
MAPULE & SICDET & AEQSLY & POICME & NRGEPT \\
IALUES & SACNLE & EULOAS & AEOLTS & PRGTLE \\
WAIBEY & WODIRY & SORECN & VRBELY & DLTRCE \\
\hline
\end{tabular}


with the constraint that no letter sequence within a nonword could form a grade $\mathbf{2}$ braille contraction. The forbidden letter sequences ranged from two to five letters in length. Some examples are: $O U$, ONG, OUND, OUGHT.

Sixteen displays were devised for each memory set size $(1,2$, or 3 target letters), or 48 regular displays in all. Eight of the 16 displays contained words, and eight contained nonwords. No target was present on three of the eight displays, and a target was present once (at a different row in each case) in each of the other five displays. The target letter never appeared in the first serial position in the six-letter item, and it had the same item location and within-item serial position for corresponding word and nonword displays.

In devising each display, three different letters were sampled at predesignated serial positions from the set of 100 words or nonwords. The 25 words or nonwords for the display then were randomly sampled from the same set, with the constraint that no word or nonword could contain any of the three potential target letters. On target-present displays, a word or nonword containing a target letter was inserted in the display. The target letter presented always was a member of the memory set, whereas the other two potential target letters were included only if the memory set size was 2 or 3 . The three potential target letters were excluded from all displays, regardless of memory set size, however, so that the greater homogeneity of display thus produced would be present on all trials. In addition to the 48 regular displays, whose order of presentation was randomized, there were four initial practice displays. Subjects also searched through several sample typewritten displays before the session.

Procedure. Subjects were asked to search as rapidly as possible, but not at the expense of accuracy, responding "yes" as soon as they had detected any one of the 1,2 , or 3 predesignated target letters or "no" after scanning the last item without finding a target letter. Half of the subjects responded "yes" with a left-hand buttonpress and "no" with a right-hand buttonpress, and the other half had the reverse hand assignment. The importance of responding "no" immediately, without backtracking to recheck the display, was emphasized. Subjects were asked to scan each row left to right, starting at the top row and working down.

Prior to each trial, the memory set of 1, 2, or 3 target letters was shown for $5 \mathrm{sec}$ in the upper-left corner of the display region, followed by a blank interval of $.5 \mathrm{sec}$ and then the display itself, which remained in view until the subject responded. During the 4-sec interval between trials, the subject received feedback on the accuracy of the response.

Subjects. Twenty-four Ohio State University undergraduates participated in order to receive course credit. Data on three additional subjects were excluded, one for failure to follow instructions and two because their overall error rate exceeded $30 \%$. All subjects had at least $20 / 30$ vision (corrected), as tested with a Snellen chart.

\section{Results}

Search time. Mean search time per six-letter item was significantly less for words than for nonwords $[F(1,23)=44.67, p<.001]$. Memory set size also had a significant effect $[F(2,46)=66.09, p<.001]$, but the word vs. nonword $x$ memory set size interaction was not significant $(F<1)$. As Figure 2 shows, the word and nonword functions were nearly parallel, with the word advantage somewhat larger when the memory-set size was $1(98 \mathrm{msec})$ rather than $2(73 \mathrm{msec})$ or $3(65 \mathrm{msec})$. To verify that the present task produced a word advantage with unpracticed subjects even when the memory set size exceeded 1 , separate analyses were conducted for each memory set size. The $13.58 \%$ time savings for words with a memory

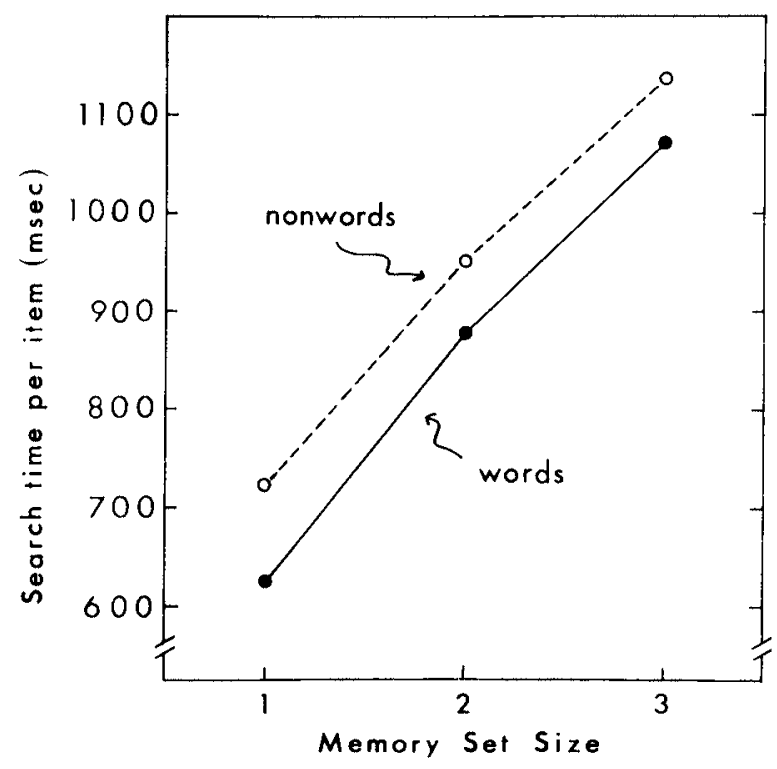

Figure 2. Experiment 2: Mean search time per item (milliseconds) by memory set size.

set size of 1 was significant $[\mathrm{F}(1,23)=24.39, \mathrm{p}<.001]$, as also were those with a memory set size of $2[F(1,23)$ $=13.07, \mathrm{p}<.01]$ and a memory set size of $3[\mathrm{~F}(1,23)$ $=6.23, \mathrm{p}<.025]$.

Errors. For a memory set size of 1, 2, and 3, respectively, the error rates on words were $12.50 \%, 23.96 \%$, and $28.65 \%$, whereas those on nonwords were $10.42 \%$, $21.35 \%$, and $28.13 \%$. Errors were slightly, but insignificantly, higher on words $(21.70 \%)$ than on nonwords $(19.97 \% ; F<1)$, so the faster search through words cannot be attributed solely to a less careful search through words, owing to overconfidence, etc. Memory set size had a highly significant main effect $[F(2,46)=24.48, p<.001]$, but did not interact with words vs. nonwords $(F<1)$. Furthermore, misses on target-present trials $(31.66 \%)$ far exceeded false alarms on target-absent trials $(2.78 \% ; \mathrm{p}<.001$, two-tailed sign test). The miss rate was $16.25 \%, 35.00 \%$, and $43.75 \%$ on memory set sizes of 1,2 , and 3 , respectively, which indicates how much more difficult the multitarget conditions were.

\section{Discussion}

In Experiment 2, excluding words having letter patterns that form contractions in grade 2 braille did not thereby eliminate the word advantage with print displays. Thus, the present materials could be meaningfully tested in Experiment 3 with braille displays. Typical time savings for six-letter common words fall in the 50- to 100-msec range (Krueger, 1970c), which the present results confirmed. Furthermore, the word advantage remained fairly steady and did not increase as the memory set size increased, thereby ruling out the comparison stage as a possible locus of 
the familiarity effect. Subjects thus encoded the words more rapidly than they did the nonwords.

Errors were slightly higher on words, but this tendency was too small and unreliable to be used to argue that search was faster through words simply because it was less careful on words. The subjects kept errors remarkably constant for the two display conditions, letting search time alone manifest a familiarity effect. On memory set size, however, errors as well as RT varied significantly. Subjects did not sufficiently slow their search for 2 or 3 letters so as to moderate the high miss rates. The greater rarity of memory matches may have lulled subjects into ignoring the target when it appeared (cf. Krueger \& Shapiro, 1980b). With a 150-letter display and a 3letter memory set, there would be 450 memory comparisons, only one of which might involve a target letter.

Given the high error rate, are the search time data meaningful? The present task may have unfairly exaggerated the errors, since an error could be triggered by an incorrect decision made on any one of 150 letters in the display, or on any one of up to 450 memory comparisons. The orderly nature of the search time functions in Figure 2 attests to the meaningfulness of the latency data, although the moderate, but insignificant, decrease in the word advantage with increased memory set size suggests that, as the task became more difficult, subjects could not fully utilize their familiarity with words to hasten encoding.

Keeping the memory set constant for a large, 25item display undoubtedly made the task easier, and this may have enabled the unpracticed subjects to encode words as words even when looking for more than one letter. When the memory set letters are highly practiced, variation in memory set size typically produces a logarithmic, rather than linear, function (Krueger \& Shapiro, 1980b), and the fact that the present function (see Figure 2) fell halfway between logarithmic and linear suggests that much of the requisite practice can be obtained on a single long scan. When questioned after the session, 22 of the 24 subjects said they kept saying the target letters to themselves as they scanned through the array.

Most (18) subjects said afterward that they saw the six-letter item as a whole on some trials, but scanned it letter-by-letter on other trials. Sixteen of the 18 said that they shifted toward letter-by-letter scanning when the memory set size increased, and 16 said there was a greater tendency to see the item as a whole when a word was shown. Subjects searched for a letter shape about $60 \%$ of the time, and for a letter sound the other $40 \%$, according to their reports. Search for shape vs. sound did not depend on display type for 8 subjects, but for 15 of the other 16 subjects there was a greater tendency to rely on sound with words than with nonwords. The comparison thus may have been more cognitive and less perceptual for words than for nonwords, although it apparently was performed equally accurately for words and nonwords, as the errors indicate, and equally rapidly as well, as the parallel functions in Figure 2 indicate. Previous work also has shown that some subjects search for letter sounds rather than letter shapes in an ostensibly visual task (e.g., Krueger, 1970b).

\section{EXPERIMENT 3}

It did not seem feasible to use memory set sizes of 2 and 3 with braille readers. Multitarget search is very difficult with print, as Experiment 2 showed, and likely would be even more difficult with braille. Therefore, in Experiment 3, as in Experiment 1, only a memory set size of 1 was used.

\section{Method}

Stimulus materials. One set of print displays (48 regular, 4 practice) used in Experiment 2 was copied in braille. Since the number of target letters was always one, if two or three targets had been specified for a print display, only one was retained (i.e., the one that actually appeared in the display; if none appeared, one was selected at random).

Braille characters were embossed on standard, $11 \times 11.5$ in. sheets of heavyweight manila paper with a Perkins Brailler. To check for typing errors, the sheets were compared against the same set of displays printed by computer.

The sheets were typed as follows. Starting at the upper-left corner in the sheet, four periods were typed in a vertical column. On the fifth row, the word "target" was typed, followed, after a blank space, by the target letter. On the succeeding 10 rows, the leftmost character again was a period, followed, after a blank space, by a string of letter characters on 5 of the 10 rows (Rows 7 , $9,11,13,15$ ).

Each braille character, or cell, was $.4 \mathrm{~cm}$ wide and $.6 \mathrm{~cm}$ high; the horizontal separation between cells was $.2 \mathrm{~cm}$, and the vertical separation between adjacent (double-spaced) rows was $1.35 \mathrm{~cm}$. Eight subjects felt the original typed sheets, and three subjects felt a set of Thermoform copies.

Procedure. The same procedure was used as in Experiment 1, except that the subjects were told that no letter sequence which formed a contraction in grade 2 braille would be used.

Subjects. Eleven blind adults, familiar with braille and ranging in age from 20 to 53 years, served as volunteer subjects. Five were tested in Louisville, Kentucky, and the other six in Columbus, Ohio. Three of the latter six had served as subjects several months previously in Experiment 1 as well.

\section{Results}

Search time. Letter search was significantly faster through words than through nonwords $[F(1,10)=$ $33.77, \mathrm{p}<.001]$. Search time increased significantly as the target was located farther down in the five rows or was not present at all $[F(5,50)=95.02, p<$ $.001]$, and location interacted significantly with the word advantage $[F(5,50)=7.86, p<.001]$, which progressively increased as the target letter was moved farther down the display (see Figure 3 ). The percent time savings for words ranged from $5.42 \%$ to $24.94 \%$ for individual subjects, and was $15.23 \%$ overall. Two-tailed sign tests of the search time difference between the 24 corresponding word and nonword dis- 


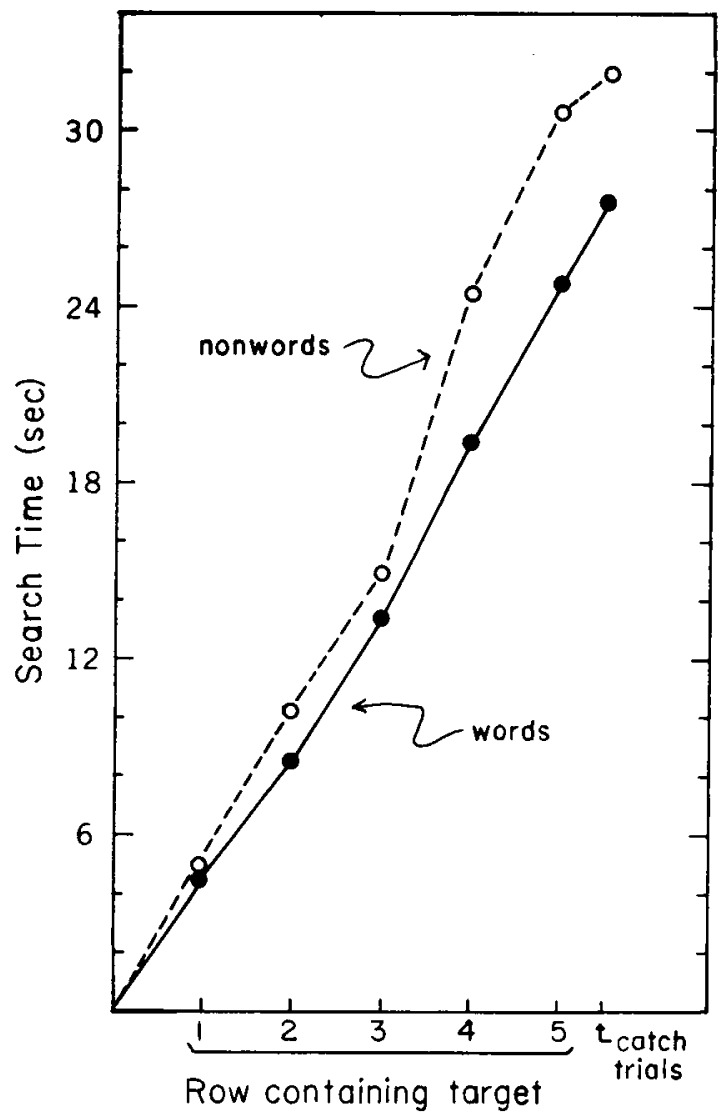

Figure 3. Experiment 3: Mean search time (seconds) by row position of target letter.

plays (excluding any pair containing an error) indicated that the speed advantage for words was very significant for six subjects $(\mathrm{p}<.001)$, quite significant for one $(p=.026)$, moderately significant for two $(p=.042)$, marginally significant for one $(p=.096)$, and not significant for one $(p=.238)$.

Errors. Errors were significantly higher for nonwords $(11.74 \%)$ than for words $(4.92 \%) ; 9$ subjects made one to three more errors on nonwords than on words, 1 subject made one more error on words than on nonwords, and 1 subject made no errors at all $(p=.021$, two-tailed sign test). The 10 subjects who made errors all had a higher error rate on targetpresent trials (misses) than on target-absent trials (false alarms), $12.73 \%$ vs. $1.01 \%$ ( $p<.002$, twotailed sign test).

\section{Discussion}

Letter search was only half as fast through a braille display in Experiment 3 (see Figure 3) as through a comparable print display in Experiment 2 (see Figure 2), and other differences (e.g., on errors, possibility of preview) also distinguished the two experiments, but even so the percent time savings for words was remarkably similar for braille in Experiment 3 $(15.23 \%)$ and print in Experiment $2(13.58 \%)$. A similar identity was noted in Experiment 1. Thus, constancy in percent time savings for a particular set of words may apply across modalities (touch, vision) as well as across age groups (children, adults) (Krueger, 1979; Krueger et al., 1974).

The $15 \%$ time savings for words found with the new materials used in Experiments 2 and 3 exceeds the $10 \%$ time savings typically found for common words in braille (Experiment 1) and print (Krueger et al., 1974). Eliminating words and nonwords with letter sequences that form contractions in grade 2 braille ensured that few nonwords would contain familiar bigrams or trigrams, but apparently did not reduce the familiarity value of the words used. Thus, when items compatible with grade 2 braille were presented under standard conditions for braille in Experiment 3, a word advantage was found. The results in Experiment 3 thus confirm those of Experiment 1 and indicate again that braille, like print, is processed in neither an overly holistic fashion nor an overly analytical fashion.

Print readers in Experiment 2 adjusted their search rates so as to keep errors about equal for the word and nonword displays. Braille readers in Experiment 3 did not do likewise, although they showed a comparable (about 15\%) percent time savings for word displays. The braille readers slowed their search considerably on nonword displays, but not enough to equalize the errors, so the "true" percent time savings for braille words may exceed $15 \%$. Given the limitations on braille processing at the sensory and perceptual levels, there perhaps would have been little prospect of detecting more target letters even if the search through nonwords had been much slower.

Braille characters are felt sequentially, whereas print characters are seen and identified in parallel, and this may have increased the word advantage for some braille readers. Several of the braille subjects said afterward that words were easier to search through than nonwords because, with words, they could anticipate whether the target character would be present or not.

\section{REFERENCE NOTES}

1. Nolan, C. Y., \& Kederis, C. J. Perceptual factors in braille word recognition (American Foundation for the Blind Research Series, No. 20). New York: American Foundation for the Blind, 1969.

2. Greenberg, S. N., \& Krueger, L. E. Effect of letter orientation and sequential redundancy on the speed of letter search. Manuscript in preparation, 1982.

3. Sternberg, S., \& Scarborough, D. L. Parallel testing of stimuli in visual search. Paper presented at the International Symposium on Visual Information Processing and Control of Motor Activity, Sofia, Bulgaria, July 1969.

\section{REFERENCES}

Cattell, J. M. The time taken up by cerebral operations. Mind, $1886,11,220-242,377-392$, and $524-538$.

Fischler, I. Detection and identification of words and letters in 
simulated visual search of word lists. Memory \& Cognition, 1975, 3, 175-182.

Foulxe, E. Reading braille. In W. Schiff \& E. Foulke (Eds.), Tactual perception: A sourcebook. New York: Cambridge University Press, 1982.

Hill, J. W. Limited field view in reading lettershapes with the fingers. In F. A. Geldard (Ed.), Cutaneous communication systems and devices. Austin, Tex: Psychonomic Society, 1974.

Johnson, N. F. On the function of letters in word identification: Some data and a preliminary model. Journal of Verbal Learning and Verbal Behavior, 1975, 14, 17-29.

Katz, D. Der Aufbau der Tastwelt. Zeitschrift für Psychologie, 1925 , Ergänzungsband 11, 270 pp.

Kirman, J. H. Tactile communication of speech: A review and an analysis. Psychological Bulletin, 1973, 80, 54-74.

KRUEGER, L. E. Search time in a redundant visual display. Unpublished doctoral dissertation, Harvard University, 1969.

Krueger, L. E. David Katz's Der Aufbau der Tastwelt (The world of touch): A synopsis. Perception \& Psychophysics, 1970, 7, 337-341. (a)

KRUEGER, L. E. The effect of acoustic confusability on visual search. American Journal of Psychology, 1970, 83, 389-400. (b)

KrUEgER, L. E. Search time in a redundant visual display. Journal of Experimental Psychology, 1970, 83, 391-399. (c)

KRUEGER, L. E. Familiarity effects in visual information processing. Psychological Bulletin, 1975, 82, 949-974.

KRUEgER, L. E. Features versus redundancy: Comments on Massaro, Venezky, and Taylor's "Orthographic regularity, positional frequency, and visual processing of letter strings." Journal of Experimental Psychology: General, 1979, 108, 125130.

Krueger, L. E. Tactual perception in historical perspective: David Katz's world of touch. In W. Schiff \& E. Foulke (Eds.), Tactual perception: A sourcebook. New York: Cambridge University Press, 1982.

Krueger, L. E., KeEn, R. H., \& Rublevich, B. Letter search through words and nonwords by adults and fourth-grade children. Journal of Experimental Psychology, 1974, 102, 845-849.

KRUEGer, L. E., \& Shapiro, R. G. Repeating the target neither speeds nor slows its detection: Evidence for independent channels in letter processing. Perception \& Psychophysics, 1980, 28, 68-76. (a)

Krueger, L. E., \& Shapiro, R. G. Why search for target absence is so slow (and careful!): The more targets there are, the more likely you are to miss one. Journal of Experimental Psychology: Human Perception and Performance, 1980, 6, 662-685. (b)

Kučera, H., \& Francis, W. N. Computational analysis of present-day American English. Providence, R.I: Brown University Press, 1967.

Lappin, J. S., \& Foulke, E. Expanding the tactual field of view. Perception \& Psychophysics, 1973, 14, 237-241.

Levin, H., \& Kaplan, G. J. Grammatical structure and reading. In $\mathrm{H}$. Levin \& $\mathrm{J}$. Williams (Eds.), Basic studies in reading. New York: Basic Books, 1970.

Loomis, J. M. On the tangibility of letters and braille. Perception \& Psychophysics, 1981, 29, 37-46.

Millar, S. Aspects of memory for information from touch and movement. In G. Gordon (Ed.), Active touch. The mechanism of recognition of objects by manipulation: $A$ multi-disciplinary approach. Oxford: Pergamon Press, 1978.

Pick, A. D., Thomas, M. L., \& Pick, H. L., Jr. The role of grapheme-phoneme correspondence in the perception of braille. Journal of Verbal Learning and Verbal Behavior, 1966, 5, 298-300.

Pillsbury, W. B. A study in apperception. American Journal of Psychology, 1897, 8, 315-393.

RÉvész, G. Psychology and art of the blind (H. A. Wolff, trans.), London: Longmans, Green, 1950.

Shiffrin, R. M., \& Gardner, G. T. Visual processing capacity and attentional control. Journal of Experimental Psychology, $1972,93,72-82$.

Theios, J., \& Muise, J. G. The word identification process in reading. In N. J. Castellan, D. B. Pisoni, \& G. R. Potts (Eds.), Cognitive theory (Vol. 2). Hillsdale, N.J: Erlbaum, 1977.

(Manuscript received September 23, 1981; revision accepted for publication January 5, 1982.) 